\title{
Regulation of the pAD1-Encoded Sex Pheromone Response in Enterococcus faecalis: Expression of the Positive Regulator TraE1
}

\author{
KOICHI TANIMOTO ${ }^{1} \uparrow$ AND DON B. CLEWELL ${ }^{1,2 *}$ \\ Department of Biologic and Materials Sciences, School of Dentistry, ${ }^{1}$ and Department of \\ Microbiology/Immunology, ${ }^{2}$ School of Medicine, The University of Michigan, \\ Ann Arbor, Michigan 48109-0402
}

Received 28 August 1992/Accepted 30 November 1992

\begin{abstract}
pAD1 is a conjugative, $60-\mathbf{k b}$, hemolysin-bacteriocin plasmid in Enterococcus faecalis that encodes a mating response to a small peptide sex pheromone, CAD1, secreted by potential recipient bacteria. The response is regulated by a cluster of genes that includes a positive regulatory determinant, traE1, able to activate key structural genes involved in the conjugative process. A negative regulatory determinant, traA, affects the expression of traE1 and is sensitive to the pheromone signal. Between the two determinants is a gene, iad, which encodes a small peptide, iAD1, a competitive inhibitor of CAD1. The determinants (traE1-iad-traA) are oriented such that iad and traE1 are transcribed in the same direction, opposite that of traA. Transcription of iad and traA starts between these determinants and moves outward in each case. A recent report from our laboratory, dealing with transcriptional fusions in the traE1-iad region (L. T. Pontius and D. B. Clewell, J. Bacteriol. 174:3152-3160, 1992), indicated that traE1 expression may be dependent on transcriptional read-through of a terminator(s) between iad and traE1. The present report provides direct analyses of relevant RNA species before and during induction and shows that indeed transcriptional read-through from iad is important in the initial expression of traE1. However, the data show that once traE1 is activated, it can then be expressed independently, probably because of TraE1 activating its own promoter. This view is also supported by genetic complementation studies. In addition, DNA binding studies with TraA showed that the protein binds to the promoter of iad. Binding of TraA to the region between iad and traE1 could not be detected; however, the involvement of TraA in influencing transcription termination in this region is still not ruled out, since additional factors could be involved. A model for the regulation of the pheromone response is presented.
\end{abstract}

pAD1 is a conjugative, $60-\mathrm{kb}$, hemolysin-bacteriocin plasmid believed to contribute to virulence in the opportunistic pathogen Enterococcus faecalis (for recent reviews, see references 4 and 9). Like a number of other $E$. faecalis plasmids that are transferred at a high frequency in broth matings, $\mathrm{pAD} 1$ encodes a response to a specific peptide sex pheromone (cAD1 in this case [21]) secreted by potential recipients. Induction results in the synthesis of a surface "aggregation substance" that facilitates the formation of mating aggregates $(13,16)$. cAD1 also activates genes required for DNA transfer and surface exclusion $(6,12)$. Donor cells secrete a peptide, iAD1, which acts as a competitive inhibitor of the pheromone; however, inhibition is significant only when cAD1 concentrations are relatively low $(5,18$, 20).

Genetic analyses with Tn917 and Tn917lac have found that all the determinants relating to conjugation are contiguously located on a region occupying at least half of the plasmid (approximately $30 \mathrm{~kb}$ ), with the genes responsible for regulation of the process being clustered in a 7-kb segment at one end $(12,17,22,28-30)$. Key regulatory genes that have been identified include (i) traE1, which encodes a positive regulator necessary for the expression of all conjugation functions (24); (ii) $\operatorname{tra} A$, which is involved in the negative control of traE1 expression $(23,30)$; (iii) $t r a B$, which is involved in the shutdown of endogenous cAD1

\footnotetext{
* Corresponding author.

$\dagger$ Present address: Department of Microbiology, Gunma University School of Medicine, Maebashi City, Gunma 371, Japan.
}

production $(30,31)$; and (iv) tra $C$, which encodes a product involved in binding to and/or sensing of exogenous pheromone $(4,30)$. In addition, the determinant for $\mathrm{iAD} 1$, iad, is located between traE1 and traA and encodes a 22-aminoacid precursor, with the last 8 residues corresponding to the active product (7). The determinants are arranged as traE1iad-traA-traC-traB, with all but tra $A$ being in a right-to-left (5'-to-3') orientation. Analyses of the nucleotide sequence and transcriptional fusions relating to the traE1-iad-traA region $(7,23,24)$ suggested that the TraA protein, which shows limited homology to certain DNA binding proteins (23), controls traE1 expression by regulating transcriptional read-through from the promoter that drives iad. The sequence data identified two apparent factor-independent transcription termination sites located close together and between iad and traE1. lacZ fusions on the downstream side (traE1 side) of the first terminator (TTS1) were inducible, while upstream derivatives (iad side) were expressed at a relatively high level in the absence of the pheromone (24). It was suggested that TraA may exert its effect via an interaction with DNA somewhere within the few hundred nucleotides separating the end of the iad reading frame and TTS1, a region that appears devoid of any other obvious terminators but that could possibly give rise to some complex RNA secondary structure (24). Induction could be viewed as facilitating an increased level of transcription through TTS1 (as well as the closely located TTS2), leading to expression of downstream traE1.

Here we present results from both genetic and biochemical analyses further detailing the regulation of traE1 tran- 
TABLE 1. Bacterial strains and plasmids used in this study

\begin{tabular}{|c|c|c|}
\hline Strain or plasmid & Relevant feature(s) & Source or reference \\
\hline \multicolumn{3}{|l|}{ Strains } \\
\hline \multicolumn{3}{|l|}{ E. faecalis } \\
\hline OG1X & str gel & 18 \\
\hline FA2-2 & rif fus & 8 \\
\hline UV202 & rif fus $\mathrm{Rec}^{-}$(derived from $\mathrm{JH} 2-2$ ) & 34 \\
\hline \multicolumn{3}{|l|}{ E. coli } \\
\hline XL1-Blue & F::Tn10 proA $A^{+} B^{+}$lacI $\triangle($ lacZ)M15/recA endA gyrA thi hsdR supE relA lac & Stratagene \\
\hline TH688 & CSH57b thr::Tn5 & 26 \\
\hline $\mathrm{DH} 5 \alpha$ & $\begin{array}{l}\mathrm{F}^{-} \phi 80 \text { lacZ } \mathrm{M} 15 \text { endA1 recA1 hsdR1 }\left(\mathrm{r}_{\mathrm{K}}^{-} \mathrm{m}_{\mathrm{K}}^{+}\right) \text {supE44 thi-1 } d^{-} \text {gyrA96 } \Delta(\text { lacZYA- } \\
\text { argF)U169 }\end{array}$ & $\begin{array}{l}\text { Promega Research } \\
\text { Laboratories; } 23\end{array}$ \\
\hline \multicolumn{3}{|l|}{ Plasmids } \\
\hline pBluescriptSK & E. coli vector plasmid; $a m p$ & Stratagene \\
\hline pAD1 & hly-bac; pheromone response & 27 \\
\hline pAM1.3SK & Fragment containing traE1 and iad (no promoter) cloned in pBluescriptSK & 7 \\
\hline pAM1.3SK $\Delta \mathrm{XbaI}$ & Deletion derivative of pAM13SK; lacks traE1, TTS1, and TTS2 & This study \\
\hline pAM1.6SK & Fragment containing traE1 and iad cloned in pBluescriptSK & 7 \\
\hline pAM2011 & pAD1 with a Tn917lac insertion affecting traE1 & 28 \\
\hline pAM2120 & pAD1 containing traA/A120 Tn917lac & 28 \\
\hline pAM2145 & pAD1 containing NR5 and M14 Tn917lac insertions & 30 \\
\hline pAM2180 & pAD1 containing a PR18 Tn917lac insertion & 28 \\
\hline pAM2604 & Bam HI fragment of pAM 2145 cloned in pAM401 & This study \\
\hline pAM2609 & XbaI-Bam HI fragment of pAM 2180 cloned in pAM401 & This study \\
\hline pAM2610 & AluI fragment (134 to $395 \mathrm{bp}$; see Fig. 3) cloned in the SmaI site of pBluescriptSK & This study \\
\hline pAM2611 & pAM2604 traA::Tn5 & This study \\
\hline pAM2622 & Cointegrate of pAM401 and pAM1.3SK at BamHI sites & This study \\
\hline pAM2623 & Cointegrate of pAM401 and pAM1.6SK at BamHI sites & This study \\
\hline pAM401 & Shuttle vector for $E$. coli and $E$. faecalis & 33 \\
\hline pAM7500 & HindIII fragment of pAD1 cloned in pBluescriptSK & 23 \\
\hline pAM7520 & $\begin{array}{l}\text { Nested deletion derivative of pAM7500 containing part of the traE1 gene; lacks the } 5 \text { ' } \\
\text { end of traE1 }\end{array}$ & This study \\
\hline pAM7557 & $\begin{array}{l}\text { Nested deletion derivative of pAM7500; traA is downstream of the lacZ promoter of } \\
\text { pBluescriptSK }\end{array}$ & This study \\
\hline
\end{tabular}

scription by TraA. The data support the view that induction indeed results in a necessary extension of transcription through the above-noted termination sites but that this process subsequently yields to the expression of traE1 from its own promoter located within TTS2. TraA was found to bind to DNA in the promoter region of iad, but an association downstream, closer to TTS1, could not be detected. The results of complementation studies involving both $\operatorname{tra} A$ and traE1 are also presented.

\section{MATERIALS AND METHODS}

Bacterial strains, plasmids, and media. The strains and plasmids used in this study are listed in Table 1. Media used for $E$. faecalis were Todd-Hewitt broth (Difco Laboratories, Detroit, Mich.) and N2GT (nutrient broth no. 2 [Oxoid Ltd., London, England] supplemented with $0.2 \%$ glucose and 0.1 $\mathrm{M}$ Tris- $\mathrm{HCl}$ [ $\mathrm{pH} 7.5])$. N2GT medium was used in all experiments involved in a pheromone response. Luria broth (10) was used for culturing Escherichia coli. Solid media were prepared by including $1.5 \%$ agar. Growth was always accomplished at $37^{\circ} \mathrm{C}$. Antibiotics were used at the following concentrations: ampicillin, $60 \mu \mathrm{g} / \mathrm{ml}$; erythromycin, $10 \mu \mathrm{g}$ $\mathrm{ml}$; chloramphenicol, $20 \mu \mathrm{g} / \mathrm{ml}$; streptomycin, $1,000 \mu \mathrm{g} / \mathrm{ml}$; and kanamycin, $40 \mu \mathrm{g} / \mathrm{ml}$.

Analysis of transcripts. RNA was prepared in a manner similar to that previously described (25). Overnight cultures of $E$. faecalis OG1X carrying the plasmid of interest were diluted to $20 \%$ in $25 \mathrm{ml}$ of N2GT medium, and the cells were grown for $2 \mathrm{~h}$. Synthetic cAD1 was then added to the cultures at a concentration of $40 \mathrm{ng} / \mathrm{ml}$. After a specified time, chloramphenicol $(200 \mu \mathrm{g} / \mathrm{ml})$ and sodium azide (20 $\mathrm{mM}$ ) were added; the cells were chilled on ice, harvested, and suspended in $2 \mathrm{ml}$ of $25 \%$ sucrose in Tris- $\mathrm{HCl}(\mathrm{pH} \mathrm{8.0)}$. After the addition of $2 \mu \mathrm{l}$ of $250 \mathrm{mM}$ EDTA (pH 8.0) and 50 $\mu \mathrm{l}$ of $20-\mu \mathrm{g} / \mathrm{ml}$ lysozyme, the cells were maintained on ice for $30 \mathrm{~min}$, pelleted, and suspended in $300 \mu \mathrm{l}$ of lysis buffer (20 $\mathrm{mM}$ Tris- $\mathrm{HCl}$ [pH 8.0], $3 \mathrm{mM}$ EDTA, $200 \mathrm{mM} \mathrm{NaCl}$ ). Three hundred microliters of lysis solution (1\% SDS [sodium dodecyl sulfate] in lysis buffer) was added, and the mixture was maintained at $100^{\circ} \mathrm{C}$ for $2 \mathrm{~min}$, with occasional mixing. Six hundred microliters of hot phenol saturated with lysis buffer $\left(65^{\circ} \mathrm{C}\right)$ was added, and the mixture was kept at $65^{\circ} \mathrm{C}$ for $5 \mathrm{~min}$, with occasional inversion of the tube. The phases were then separated by centrifugation, and the aqueous phase was extracted once with phenol-chloroform and then twice with ether. A $1 / 10$ volume of $3 \mathrm{M}$ sodium acetate was added, after which nucleic acid was recovered by ethanol precipitation. The pellet was suspended in $100 \mu \mathrm{l}$ of DNase I buffer ( $100 \mathrm{mM}$ sodium acetate, $5 \mathrm{mM} \mathrm{MgCl}_{2}$ [pH 5.0]), and DNA was digested with DNase I (RNase free; Boehringer Mannheim Biochemicals) for $2 \mathrm{~h}$ at $37^{\circ} \mathrm{C}$. RNA was recovered by ethanol precipitation. RNA species were then separated by electrophoresis in a $1.2 \%$ agarose-MOPS (3-[Nmorpholino]propanesulfonic acid)-formaldehyde system (1). Northern (RNA) hybridization was carried out at $42^{\circ} \mathrm{C}$ in the presence of $50 \%$ formamide (1). The two probes consisted of 
pAM1.3SK $\Delta \mathrm{XbaI}$ (probe 1) and pAM7520 (probe 2); these probes were labeled by nick translation with a kit from Bethesda Research Laboratories. RNA marker molecules were from Bethesda Research Laboratories.

Determination of the initiation site of transcription. Primer extension was conducted essentially as described elsewhere (1). The synthetic primer was made by the University of Michigan DNA Core Facility and corresponded to the structure 5'-CCTACAAGTGTGACAACAAATAAAGTTATC-3', which is located in the iad determinant (see Fig. 3). Primer DNA $(3.2 \mu \mathrm{g})$ was treated with $10 \mathrm{U}$ of $\mathrm{T} 4$ polynucleotide kinase (Bethesda Research Laboratories) in the presence of $200 \mu \mathrm{Ci}$ of $\left[\gamma^{-32} \mathrm{P}\right] \mathrm{ATP}(10 \mathrm{mCi} / \mathrm{ml}$; Amersham $)$. Forty two micrograms of RNA prepared from OG1X(pAD1) induced with $40 \mathrm{ng}$ of cAD1 per $\mathrm{ml}$ for $20 \mathrm{~min}$ was hybridized with 30 ng of kinase-treated primer overnight at $30^{\circ} \mathrm{C}$ in $30 \mu \mathrm{l}$ of hybridization solution (166 mM HEPES [ $N$-2-hydroxyethylpiperazine- $N^{\prime}$-2-ethanesulfonic acid] [pH 7.5], 1.0 M NaCl, 0.33 mM EDTA). Primer extension was conducted with 37.5 $\mathrm{U}$ of avian myeloblastosis virus reverse transcriptase (Boehringer-1.6 mM each deoxynucleoside triphosphate- $50 \mathrm{mM}$ Tris- $\mathrm{HCl}$ ( $\mathrm{pH} 8.0$ )-5 mM $\mathrm{MgCl}_{2}-50 \mathrm{mM} \mathrm{KCl}-5 \mathrm{mM}$ dithiothreitol-50 $\mu \mathrm{g}$ of gelatin per $\mathrm{ml}$. The reaction mixture was incubated at $42^{\circ} \mathrm{C}$ for $90 \mathrm{~min}$. Samples were run on a sequencing gel after pancreatic RNase I treatment, and the gel was autoradiographed after being dried. Related sequencing reactions were carried out as described elsewhere (2).

iAD1 production after induction. An overnight culture of FA2-2(pAD1) was diluted to $2 \%$ in $10 \mathrm{ml}$ of N2GT broth. After growth for $4 \mathrm{~h}$ at $37^{\circ} \mathrm{C}$, synthetic $\mathrm{CAD} 1$ was added at a concentration of $10 \mathrm{ng} / \mathrm{ml}$. At $0,10,20$, and $40 \mathrm{~min}$ after the addition of cAD1, $1.5-\mathrm{ml}$ samples were removed; culture supernatants were quickly prepared and boiled for $10 \mathrm{~min}$. The $\mathrm{iAD} 1$ titer was determined as previously described (18) by a microtiter assay.

Complementation studies. For studies involving the complementation of tra $A$, plasmid pAM2604 was constructed by cloning the BamHI fragment of pAM2145 in shuttle plasmid pAM401, whereas plasmid pAM2609 was prepared by cloning the $\mathrm{XbaI}$-BamHI fragment of pAM2180 in pAM401 (see Fig. 5). Tn5 mutagenesis of pAM2604 was performed as follows. The plasmid was introduced into $E$. coli TH688 (with Tn 5 in the thr locus) by transformation; transformants were streaked on selective plates and left at room temperature for 2 weeks. Plasmid DNA was prepared from a mixture of colonies and used to transform plasmid-free $E$. coli $\mathrm{DH} 5 \alpha$, with selection for kanamycin resistance (for Tn5) and vectorborne chloramphenicol resistance. Resulting colonies were purified and examined for the specific location of $\operatorname{Tn} 5$ in the plasmid. One derivative, found to have an insert in $\operatorname{tra} A$, was designated pAM2611 (see Fig. 5) and tested for complementation in $E$. faecalis. Plasmid DNA was introduced into $E$. faecalis by electroporation (22) with a Bio-Rad Gene Pulser. Complementation of the traA phenotype was determined by use of short broth matings as well as examination of colony morphology in the $E$. faecalis UV202 (recombination-deficient) background.

Complementation of the traE1 phenotype was determined with plasmids pAM2622 and pAM2623, which were generated by ligation of pAM1.3SK and pAM1.6SK, respectively, to pAM401 via the BamHI sites in each. The plasmids were then introduced into $E$. faecalis OG1X(pAM2011) by electroporation. Transformants were plated on N2GT agar containing cAD1 $(40 \mathrm{ng} / \mathrm{ml})$, erythromycin $(10 \mu \mathrm{g} / \mathrm{ml})$, and chloramphenicol $(20 \mu \mathrm{g} / \mathrm{ml})$. This procedure assured the maintenance of both pAM2011 and the test plasmid during determination of whether the colony morphology exhibited the "dry" phenotype indicative of pheromone induction. For the clumping assays, $0.5-\mathrm{ml}$ portions of overnight cultures were diluted in $4.5 \mathrm{ml}$ of fresh N2GT medium to which cAD1 was then added to a final concentration of $100 \mathrm{ng} / \mathrm{ml}$. Examination for clumping was done after $2 \mathrm{~h}$.

Overproduction and partial purification of the TraA protein. Overproduction of TraA in $E$. coli was accomplished with pAM7557, a derivative carrying traA downstream of the lacZ promoter of pBluescriptSK. The construct was generated originally as a nested deletion of pAM7500 (see reference 23 and Fig. 5). tra $A$ lacked its own promoter but maintained its ribosome binding site.

Five milliliters of an overnight culture of $E$. coli XL1Blue(pAM7557) was added to $500 \mathrm{ml}$ of Luria broth, and cells were grown for $3 \mathrm{~h}$. IPTG (isopropyl- $\beta$-D-thiogalactoside) was added to a final concentration of $1 \mathrm{mM}$ to induce transcription from the lacZ promoter, and the culture was incubated for another $5 \mathrm{~h}$. The cells were then harvested, frozen $\left(-70^{\circ} \mathrm{C}\right)$, and thawed. The pellet was suspended in 2 $\mathrm{ml}$ of A0 buffer (50 mM Tris-HCl [pH 7.5], $1 \mathrm{mM}$ EDTA, 1 $\mathrm{mM}$ dithiothreitol, $10 \%$ glycerol) and sonicated for $3 \mathrm{~min}$ at 60 to $80 \mathrm{~W}$. After the removal of particulate material by centrifugation, ammonium sulfate was added to a final concentration of $60 \%$; precipitated protein was collected by centrifugation. The protein was then dissolved in $20 \mathrm{ml}$ of PBS (140 mM NaCl, $1.5 \mathrm{mM} \mathrm{KH}_{2} \mathrm{PO}_{4}, 15 \mathrm{mM} \mathrm{Na}_{2} \mathrm{HPO}_{4}, 2.7$ $\mathrm{mM} \mathrm{KCl}$ [pH 7.4]), and the solution was dialyzed overnight against PBS. The sample was applied to a heparin-Sepharose column (10 ml; Pharmacia LKB Biotechnology) at a flow rate of $100 \mu \mathrm{l} / \mathrm{min}$, and the column was washed with $50 \mathrm{ml}$ of PBS at a flow rate of $200 \mu \mathrm{l} / \mathrm{min}$. Proteins were eluted with an $\mathrm{NaCl}$ gradient (140 mM to $2 \mathrm{M}$ in a total of $200 \mathrm{ml}$ ) in PBS and collected as 1-ml fractions. Fractions were examined for protein content by SDS-polyacrylamide gel (10\%) electrophoresis and staining with Coomassie brilliant blue. Size markers were a "rainbow set" of proteins from Amersham.

Gel retardation experiments. The DNA substrate (pAM7500) was digested with a restriction enzyme(s), extracted with phenol-chloroform, and precipitated with ethanol. DNA binding was carried out essentially as described elsewhere (1). The binding mixture contained the DNA restriction digest, 5 to 10 $\mu l$ of the TraA fraction, $10 \%$ glycerol, $1 \mathrm{mM}$ dithiothreitol, 200 $\mu \mathrm{g}$ of bovine serum albumin per $\mathrm{ml}$, and $2 \mu \mathrm{g}$ of salmon sperm DNA. The mixture was incubated at $30^{\circ} \mathrm{C}$ for $30 \mathrm{~min}$ and then examined by gel electrophoresis with $3 \%$ NuSieve (FMC BioProducts) in Tris-glycine buffer ( $50 \mathrm{mM}$ Tris- $\mathrm{HCl}$ [pH 8.5], $380 \mathrm{mM}$ glycine, $2 \mathrm{mM}$ EDTA). DNA bands were visualized under UV light after staining was done with ethidium bromide.

DNA footprinting. The AluI DNA fragment (134 to $395 \mathrm{bp}$ ) containing the $\operatorname{tra} A$ binding site was cloned in the SmaI site of pBluescriptSK, located between the BamHI and KpnI sites. The resulting plasmid was designated pAM2610. Target DNA was prepared by digestion of pAM2610 with KpnI and $\mathrm{BamHI}$, agarose gel electrophoresis, and elution of DNA from an agarose block. The BamHI cohesive end was filled in with polymerase (Klenow) in the presence of $\left[\alpha^{-32} \mathrm{P}\right] \mathrm{dATP}$. Protein-DNA binding was allowed to occur as described above for the gel retardation experiments. Magnesium and calcium ion concentrations were adjusted to 5 $\mathrm{mM}$ each. Two microliters of diluted DNase I $(50 \mathrm{ng} / \mathrm{ml})$ (Bethesda Research Laboratories) was added to $50 \mu \mathrm{l}$ of the reaction mixture, and the mixture was incubated at $25^{\circ} \mathrm{C}$ for $2 \mathrm{~min}$. The reaction was stopped by the addition of $50 \mu \mathrm{l}$ of phenol-chloroform. DNA was recovered by ethanol precipitation, suspended in $4 \mu \mathrm{l}$ of DNA sequencing buffer, and run 

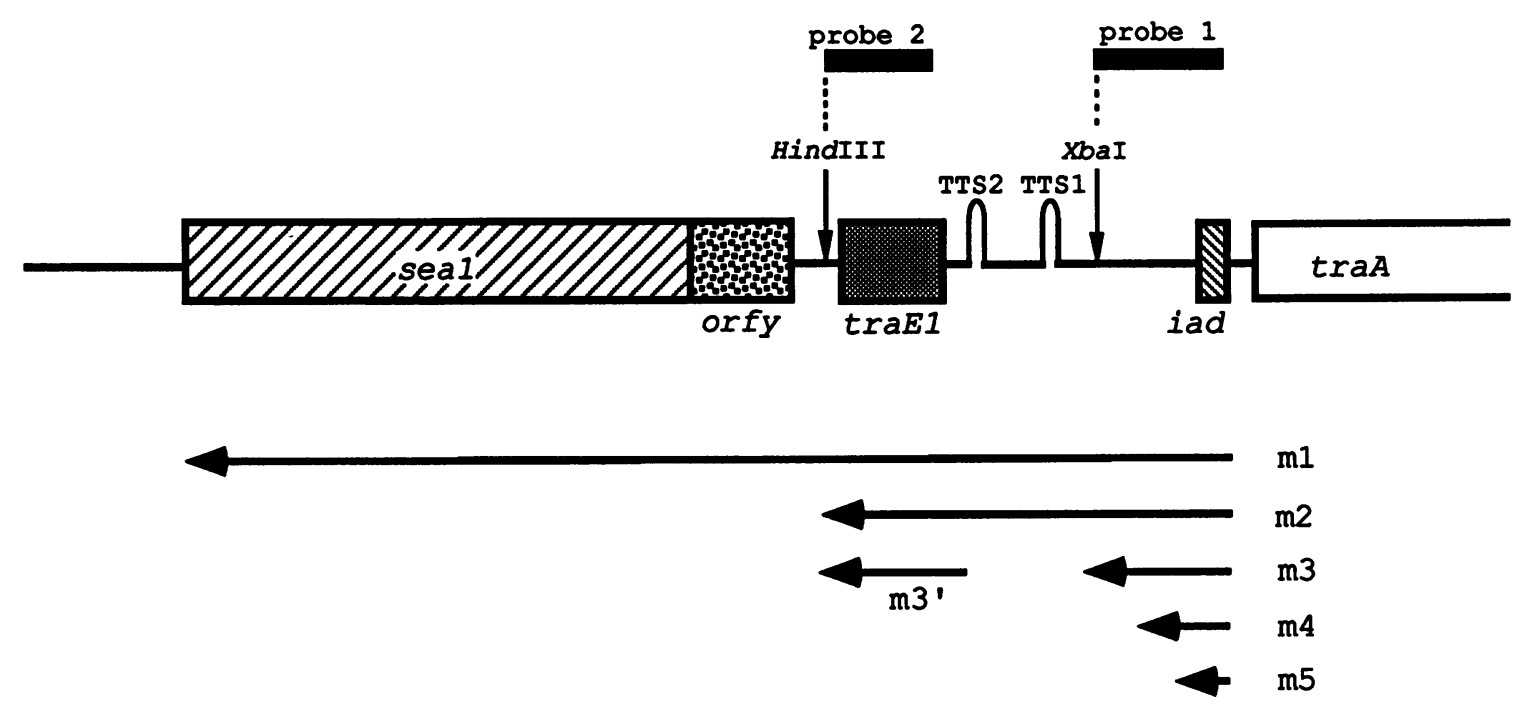

FIG. 1. Map of the key regulatory region of the pheromone response of pAD1 along with notations relevant to transcription analyses. The locations of probes 1 and 2, used in the experiments shown in Fig. 2, are indicated, and the arrows represent interpretations of the various transcripts ( $\mathrm{m} 1$ to $\mathrm{m} 5$ and $\mathrm{m}^{\prime}$ ) detected. TTS1 and TTS2 are previously identified (24) putative transcription termination sites.

alongside a DNA sequence analysis preparation. After drying was complete, autoradiography was done at $-70^{\circ} \mathrm{C}$, usually overnight.

\section{RESULTS}

Analysis of pheromone-induced transcripts. Figure 1 shows the region that was analyzed for RNA products during induction; probes 1 and 2 cover the locations indicated. The results of the Northern analyses are shown in Fig. 2A. When probe 1 (Fig. 2A), which contained iad and flanking regions, was used, three transcripts were clearly evident in uninduced cells (lane 1 ). These were designated $\mathrm{m} 3$ ( $\sim 400$ bases), $\mathrm{m} 4$ ( $\sim 170$ bases), and $\mathrm{m} 5$ ( $\sim 110$ bases). After $20 \mathrm{~min}$ of exposure to cAD1 $(40 \mathrm{ng} / \mathrm{ml})$, two additional transcripts, designated $\mathrm{ml}(\sim 4,400$ bases) and $\mathrm{m} 2$ ( $\sim 1,050$ bases), were detected (Fig. 2A, lane 2). When probe 2 (Fig. 2B) was used, no RNA was detected in uninduced cells (lane 1); however, $\mathrm{m} 1$ and $\mathrm{m} 2$, as well as a band similar in size to $\mathrm{m} 3$, here designated $\mathrm{m} 3^{\prime}$, were evident after $20 \mathrm{~min}$ of induction (lane 2 ). The $m 3^{\prime}$ transcript must be different from $m 3$, since it was barely detectable in uninduced cells. The data are consistent with the arrows in Fig. 1 indicating $\mathrm{m} 1$ through $\mathrm{m} 5$ (including $\left.\mathrm{m} 3^{\prime}\right)$. $\mathrm{m} 3$ corresponds well in size to a transcript beginning at the iad promoter and terminating at TTS1, whereas $\mathrm{m} 4$ and
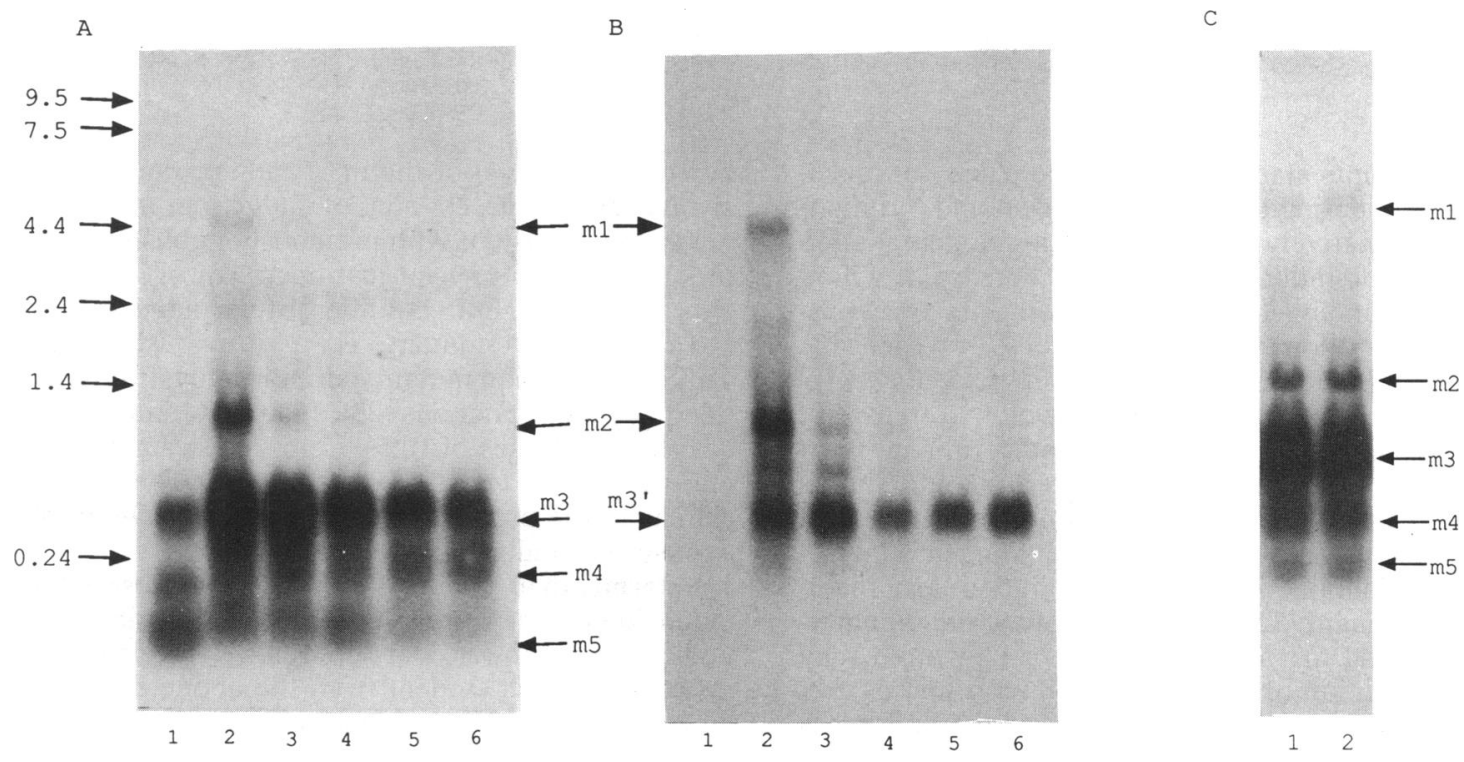

FIG. 2. Northern blot analyses of the regulatory region depicted in Fig. 1. (A and B) Wild-type pAD1 tested with probe 1 (A) and probe 2 (B). (C) traA mutant pAM2120 tested with probe 1 . In all three panels, lane 1 represents cells without the addition of cAD1, and lane 2 represents exposure to $\mathrm{CAD} 1$ for $20 \mathrm{~min}$. In panels $\mathrm{A}$ and $\mathrm{B}$, lanes 3 to 6 correspond to cAD1 exposure times of 40,80 , 120, and 160 min, respectively. Arrows indicate transcripts $\mathrm{m} 1$ to $\mathrm{m} 5$ and $\mathrm{m} 3$ '. The positions of RNA markers are noted on the left (in kilobases). 


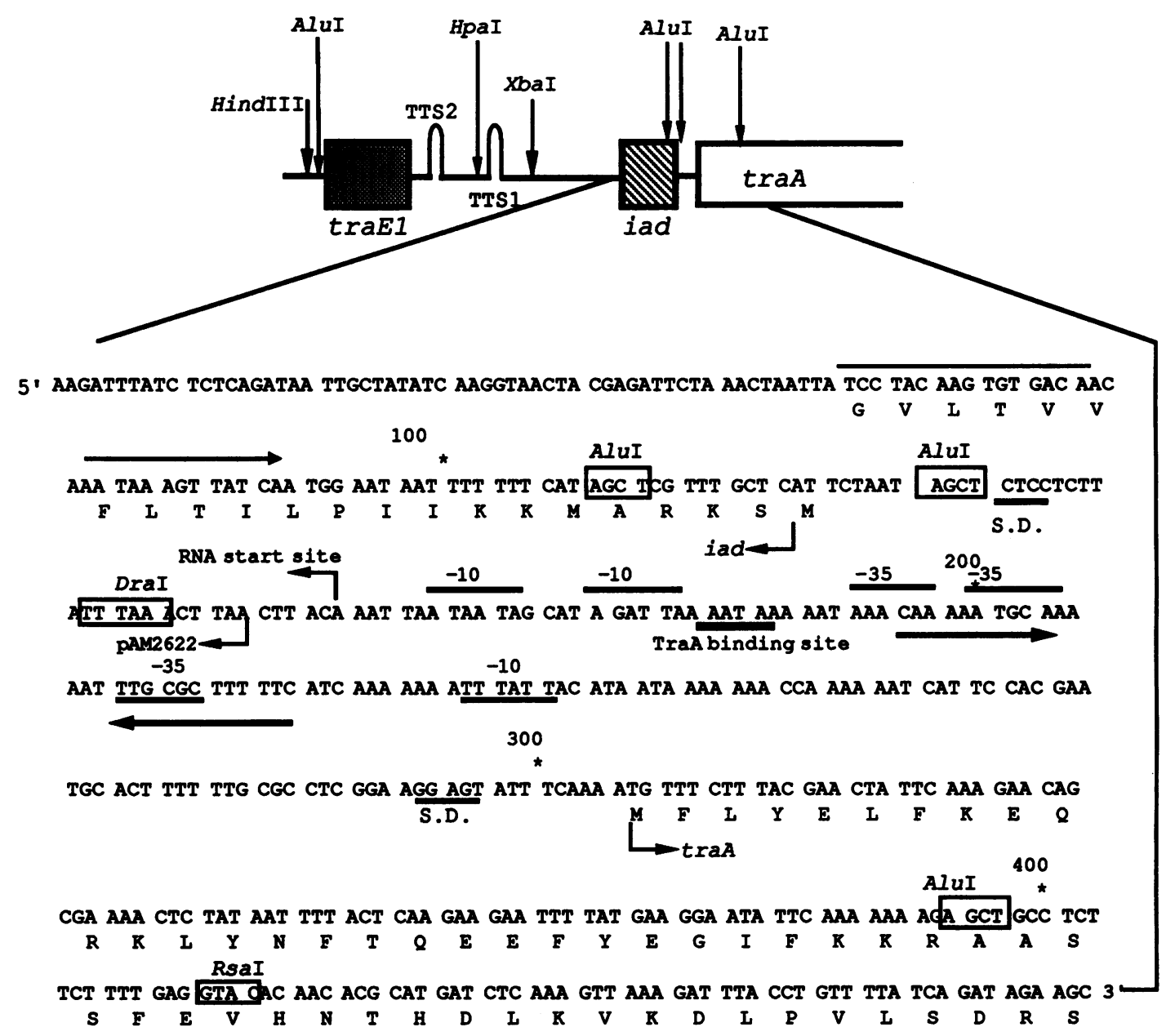

FIG. 3. Restriction map of the regulatory region of pAD1 along with the DNA sequence of the segment containing iad and a portion of traA. Putative -10 and -35 boxes and Shine-Dalgarno (S.D.) sites are noted for both traA and iad. A region of dyad symmetry between iad and traA is noted by inverted arrows. The designation pAM2622 indicates one end of the pAD1 fragment contained in pAM2622, pAM1.3SK, and pAM1.3SK $\Delta$ XbaI. The arrow above the iad sequence represents the oligomer used in the primer extension study (see Fig. 4); the deduced RNA start site is also noted. The TraA binding site relating to the data shown in Fig. 8 is shown between the -10 and -35 boxes of iad.

m5 may be transcripts starting at the same place but terminating earlier or initiating further downstream and terminating at TTS1. Alternatively, $\mathrm{m} 4$ and $\mathrm{m} 5$ may be degradation products of $\mathrm{m} 3$. The induced $\mathrm{m} 3^{\prime}$ band is consistent with a transcript corresponding to traE1 and using its own promoter and transcription termination site. (Two possible transcription termination sites are evident between traE1 and orfy [32]). The $\mathrm{m} 2$ band corresponds well to a transcript that extends through TTS 1 and TTS2 and terminates just beyond traE1, presumably at the same termination site as that used by $\mathrm{m}^{\prime}$. The $\mathrm{m} 1$ band corresponds to a transcript extending into the sea-1 determinant and ending at a factorindependent termination site that was identified near the $3^{\prime}$ end of that determinant (32). The nature of the band migrating between $\mathrm{m} 2$ and $\mathrm{m}^{\prime}$ in Fig. $2 \mathrm{~B}$ is not known. It may represent a degradation or processed product of $\mathrm{m} 1$ or $\mathrm{m} 2$.

Figure 2 also shows that the induction of $\mathrm{m} 1$ and $\mathrm{m} 2$ is maximal within $20 \mathrm{~min}$; their presence is greatly reduced after $40 \mathrm{~min}$ (lane 3 ) and barely detectable after $80 \mathrm{~min}$ (lane 4). The $m 3^{\prime}$ transcript, however, remains at a high level throughout the entire 160 -min time period. The $\mathrm{m} 4$ and $\mathrm{m} 5$ bands do not appear to change much during induction; however, the level of the $\mathrm{m} 3$ band appears to be increased significantly after $20 \mathrm{~min}$ of induction. An inducible $\mathrm{m} 3$ would be consistent with previously published analyses (24) of a lacZ fusion present just upstream of TTS1; this fusion expressed LacZ but could be further induced with CAD1.

The traA120 mutant is a previously characterized Tn917lac insertion mutant exhibiting constitutive expression of conjugation functions (28). Figure $2 \mathrm{C}$ shows the results of Northern analyses of RNA from this strain both before and after exposure to $\mathrm{CAD} 1$ for $20 \mathrm{~min}$. The profiles appear similar to the profile corresponding to a 20 -min pheromone exposure of inducible pAD1.

Determination of the initiation site of transcription. Primer extension can be used to determine transcription start sites, with the assumption that the transcript being primed is not processed. As is evident from the above-described results, all transcripts, with the exception of $\mathrm{m}^{\prime}$, can be viewed as initiating from a promoter upstream of iad (Fig. 3). Figure 4 shows the results of a primer extension analysis performed on RNA prepared after a 20-min exposure of cells to the pheromone. Transcription was found to start with a $G$ located downstream of two previously apparent -10 boxes, 


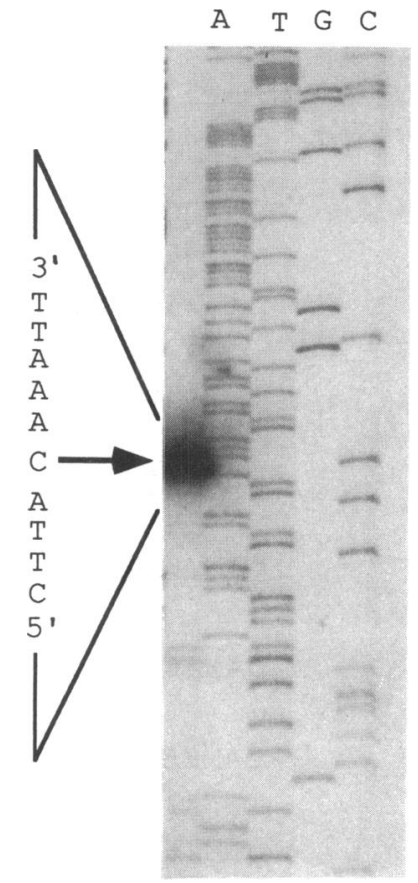

FIG. 4. Primer extension analysis. The primer used is within the iad determinant (Fig. 3). The results are shown in the leftmost lane alongside a DNA sequence determination performed with the same primer and a DNA template (pAM7500) representing this region. The specific location of the first nucleotide is noted by the arrow and is also noted in Fig. 3.

6 and 17 bases away. As noted above, there is a possibility that $\mathrm{m} 4$ and/or $\mathrm{m} 5$ initiated further downstream; however, if either species still overlapped the primer, there should have been an indication in the data in Fig. 4. Initiation further downstream of the primer would not be detected here.

Expression of iad during induction. While the transcription data imply that induction is associated with increased readthrough of TTS1, the very high level of $m 3$ present after 20 min suggests that transcription from the iad promoter is also initiated at an increased rate. Although the levels of $\mathrm{m} 4$ and m5 do not appear to differ dramatically from those observed for uninduced cells, the fact that all three transcripts represent $i a d$ raises the question of whether induction is associated with an increased production of $\mathrm{iAD} 1$. For examination of this point, FA2-2(pAD1) cells were induced for 10, 20, and $40 \mathrm{~min}$ with $10 \mathrm{ng}$ of cAD1 per $\mathrm{ml}$ and then removed by a short centrifugation step. The cAD1 titers in supernatants were then determined to ascertain whether they were decreased because of an increase in the production of $\mathrm{iAD} 1$. We observed a consistent decrease of about $50 \%$ (one dilution); thus, it is conceivable that there is some increase in iAD1 secretion, but it is not dramatic (data not shown). (It is important to note that this type of experiment must be done with the FA2-2 host rather than the isogenically different OG1-related hosts. CAD1 and $\mathrm{ADD} 1$ both bind to the surface of OG1(pAD1) cells because of a specific pheromone binding factor; however, this factor is not evident in the FA2-2 host [30]).

traA acts in trans. Although it has been assumed that the $\operatorname{tra} A$ product is a repressor that acts in trans, this assumption has not been directly confirmed by complementation experiments. Here we make use of the $\mathrm{Rec}^{-}$strain of UV202 to demonstrate that this is indeed the case. Figure 5 shows a series of chimeric plasmids containing various segments of the regulatory region. Plasmids pAM2604 and pAM2609, both of which contain $\operatorname{traA}$, were introduced into strain UV202 (by electroporation) containing pAD1 traA120, a constitutively aggregating high-frequency transfer derivative. (traA120 is a Tn917lac insertion about $25 \%$ of the way into the $5^{\prime}$ end of the gene.) Colonies of cells containing pAD1 traA120 are characteristically dry (able to be easily fractured with a toothpick) and easily distinguished from the wild type $(17,31)$. They also transfer plasmid DNA at a relatively high frequency (e.g., $\left.10^{-4}\right)$ in short (10-min) broth matings. When the cells also contained pAM2604 or pAM2609, they no longer had the dry colony appearance or transferred plasmid DNA at a high frequency in broth. However, when pAD1 traA120 was used together with pAM2611, which had a Tn5 insertion in $\operatorname{tra} A$, no complementation was observed (data not shown). (We were not able to test for inducibility in the UV202 strain because of a host-related trait that prevents the inducibility of pAD1 [17].) The observations clearly support the view that TraA acts in trans to regulate transcription into traE1 and beyond.

Partial purification of TraA. pAM7557 is a pBluescriptSK vector carrying traA on the segment indicated in Fig. 5. With traA under the control of the lac $Z$ promoter of the vector, expression could be enhanced by exposure of the $E$. coli XL1-Blue host to IPTG. After exposure to IPTG, a $40-\mathrm{kDa}$ band was detectable by SDS-polyacrylamide gel electrophoresis (PAGE); this band was not seen in a similar preparation from cells containing only the vector (data not shown) and is presumed to represent TraA. Bacterial sonicates were precipitated with ammonium sulfate $(60 \%)$ and fractionated on a heparin-Sepharose column as described in Materials and Methods. As shown in Fig. 6, a protein of the expected size was detected in fractions 24 to 26 . This band was not present in a similarly fractionated preparation from cells harboring only pBluescriptSK. Fractions 24 to 26 were combined and dialyzed against PBS, as were corresponding fractions from a control (vector only) preparation. These were used in the examination of TraA binding to DNA as described below.

DNA binding of TraA. Gel retardation studies were performed with restriction digests of pAM7500 (Fig. 5). Partially purified TraA was mixed with plasmid DNA digested with DraI or $R s a I$, after which the restriction fragments were separated by agarose gel electrophoresis (Fig. 7). The shifting of a DraI fragment (Fig. 7A) and an RsaI fragment (Fig. $7 B)$ suggested that TraA bound between these two sites in the region shown in Fig. 3. For further examination of this region, DNA was cleaved with a mixture of $A l u I$ and $H p a I$ prior to being mixed with TraA. Figure $7 \mathrm{C}$ shows that an AluI fragment corresponding in size to that bounded by positions 134 and 395 in Fig. 3 was missing (lanes 3 and 4) when TraA was present. We believe that the band was shifted as a smear (i.e., because of the dissociation of protein during migration), making it difficult to resolve on the gel. It is also important to note that the band bounded by the HpaI site just downstream of TTS1 and the AluI site at position 113 did not shift; thus, binding in the region between iad and TTS1 was not evident.

A footprinting analysis was performed as follows. The above-noted $A$ luI fragment exhibiting binding to TraA was eluted after agarose gel electrophoresis and cloned in the SmaI site in pBluescriptSK; the resulting chimera was designated pAM2610. The cloned fragment was separated by cleavage with BamHI and KpnI (which target sites flanking 


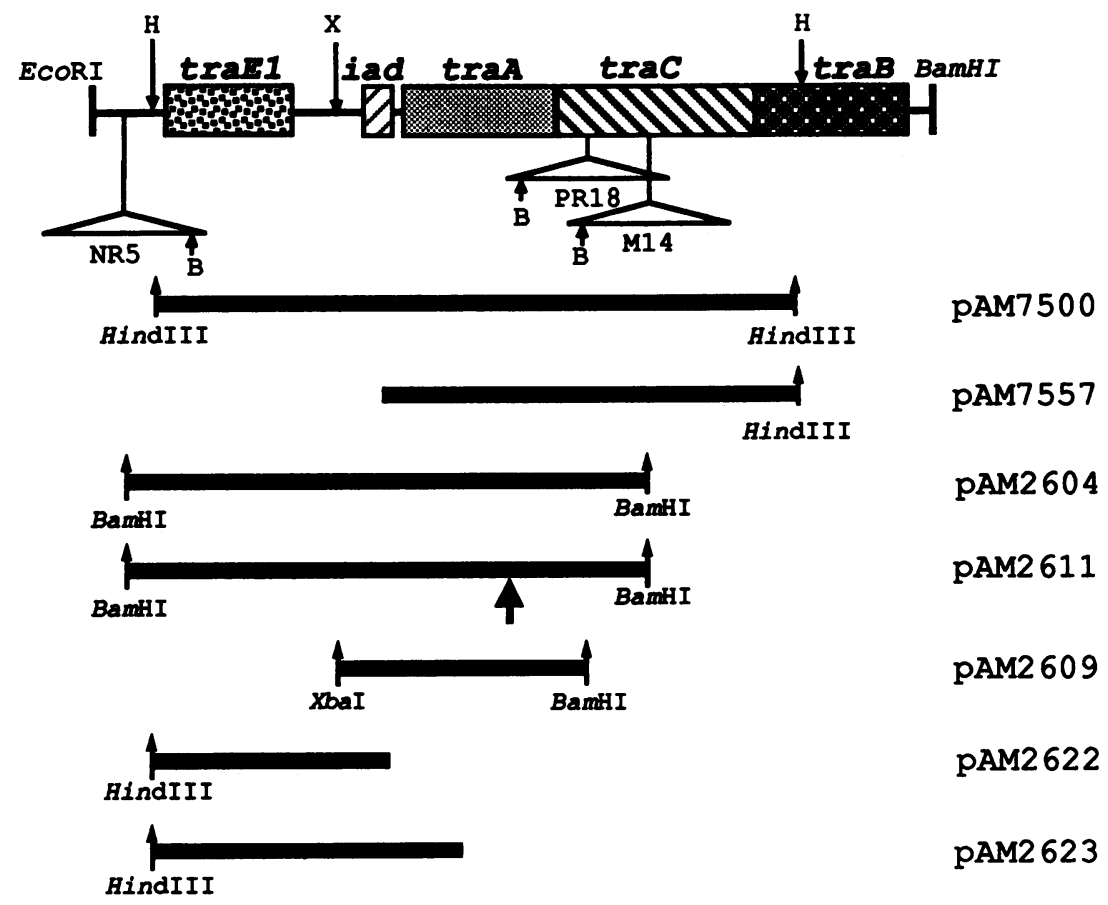

FIG. 5. pAD1 regulatory region and plasmids used for complementation and DNA binding studies. The triangles represent Tn917lac insertions that have been generated and characterized elsewhere (28); they are present in plasmids pAM2145 (NR5 and M14) and pAM2180 (PR18). The BamHI site in these insertions was used in the construction of certain plasmid derivatives. The notations for restriction sites are as follows: B, Bam HI; H, HindIII; K, KpnI; and X, XbaI. The vertical arrows on the ends of the designated plasmid segments indicate the restriction sites used for construction; the absence of an arrow indicates that the end was generated in a nested deletion process. A larger arrow for pAM2611 indicates the location of a $\operatorname{Tn} 5$ insertion.

the AluI fragment) and purified by gel electrophoresis. This fragment was then end labeled by filling in of the BamHI cohesive end with polymerase and $\left[\alpha^{32}\right.$ P]dATP. The $A l u \mathrm{I}$ 134-base site (Fig. 3) was near the labeled end; the AluI 395-base site was near the KpnI site. The labeled fragment was mixed with TraA, digested with DNase I, and analyzed by gel electrophoresis (Fig. 8). As shown in lane 1, some regions appeared protected from digestion with DNase I, even in the absence of TraA. However, a 5-base region was specifically protected in the presence of the protein (lane 2). Although faint bands were sometimes observed in this region, they were always much weaker in intensity than those in the control. The corresponding region within the sequence is indicated in both Fig. 8 and 3 and is located within the iad promoter. It was clear that the region nearer the BamHI site (or iad) was not protected. It is conceivable that there was some TraA binding nearer the KpnI site (toward the traA determinant). The presence of a segment with dyad symmetry (hairpinning potential) close to the tra $A$ promoter may protect this region, even in the absence of TraA; however, bands in this region tended to be slightly fainter when TraA was present.

Complementation of traE1. It was of interest to determine whether a mutation in traEl could be complemented in trans. In addition, since the transcriptional data and DNA binding studies implied that TraA may affect traE1 expression via influence at the iad promoter, it was important to determine genetically whether the presence of the iad promoter on the complementing DNA segment was necessary.

pAM2623 contains a segment extending from the HindIII site downstream of traE1 into traA (Fig. 5). pAM2622 is a similar clone, except that the region upstream of $i a d$, includ- ing the iad promoter, is absent. Each of these plasmids was introduced by electroporation into an OG1X host already carrying the pAD1 derivative pAM2011, which contains a Tn917lac insertion between the -10 and -35 boxes of traE1. Normally, OG1X(pAD1) cells give rise to dry colonies on plates containing cAD1, whereas cells carrying pAM2011 exhibit a typical traE1 mutant phenotype and therefore do not exhibit dry colonies on pheromone-containing plates. OG1X(pAM2011) cells also do not undergo the characteristic clumping when exposed to the pheromone for a few hours in broth. OG1X(pAM2011, pAM2623) exhibited a dry colony morphology in the presence of cAD1 $(40 \mathrm{ng} / \mathrm{ml})$; however, the colonies did not appear quite as dry as for OG1X(pAD1). Similarly, exposure to cAD1 in broth resulted in clumping, but it was clearly less dramatic than for OG1X(pAD1). In contrast, OG1X(pAM2011, pAM2622) cells were no different from OG1X(pAM2011) cells with respect to their appearance in the presence of the pheromone on plates or in broth.

The data imply that when traE1 is provided in trans it does indeed complement the mutation in pAM2011, but only if the iad promoter is also present. It would have been more desirable to perform the experiment with a $\mathrm{Rec}^{-}$host such as UV202 but, as noted earlier, the pAD1 system is not inducible in that host. Unfortunately, there is currently no $\mathrm{Rec}^{-}$host available that is isogenic with the OG1X host. Analysis of plasmid DNA from OG1X(pAM2011, pAM2263) cells provided no detectable evidence that recombination had occurred between the two plasmids (data not shown), although it is conceivable that a low level of recombination might have taken place and was responsible for the complementation observed at a lower level than might have been expected. However, this idea is not relevant to the fact that 


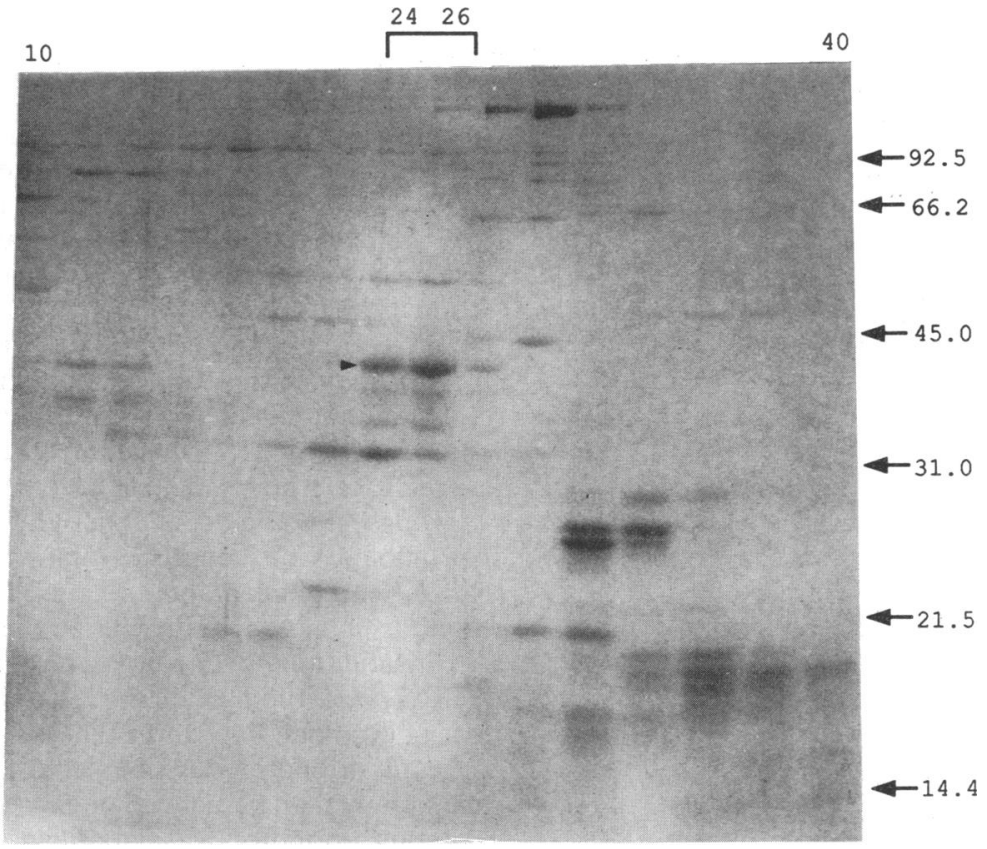

FIG. 6. SDS-PAGE of fractions from a heparin-Sepharose chromatography column used to partially purify TraA. An extract containing TraA was prepared and applied to the column as described in Materials and Methods. Aliquots $(60 \mu \mathrm{l})$ from every second fraction between fractions 10 and 40 were analyzed. (Fraction numbers are indicated on the top.) The arrowhead points to the TraA protein, which was absent in similarly prepared fractions from a control strain containing only vector DNA. The arrows on the right indicate the molecular masses (in kilodaltons) of marker proteins.

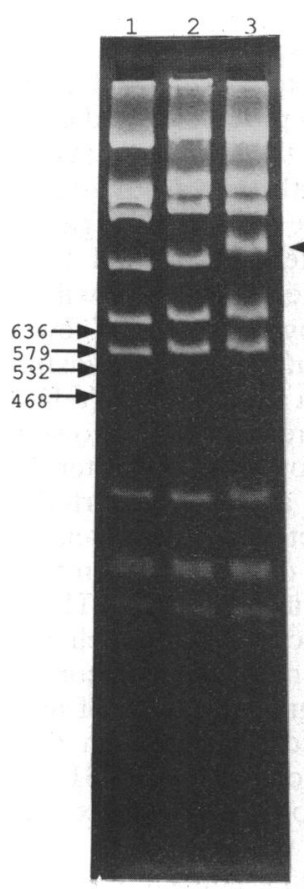

A

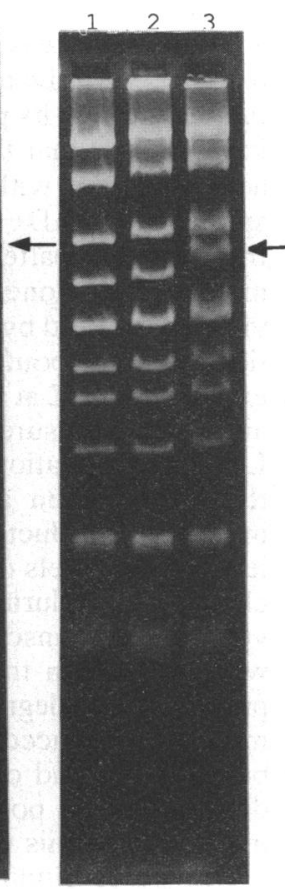

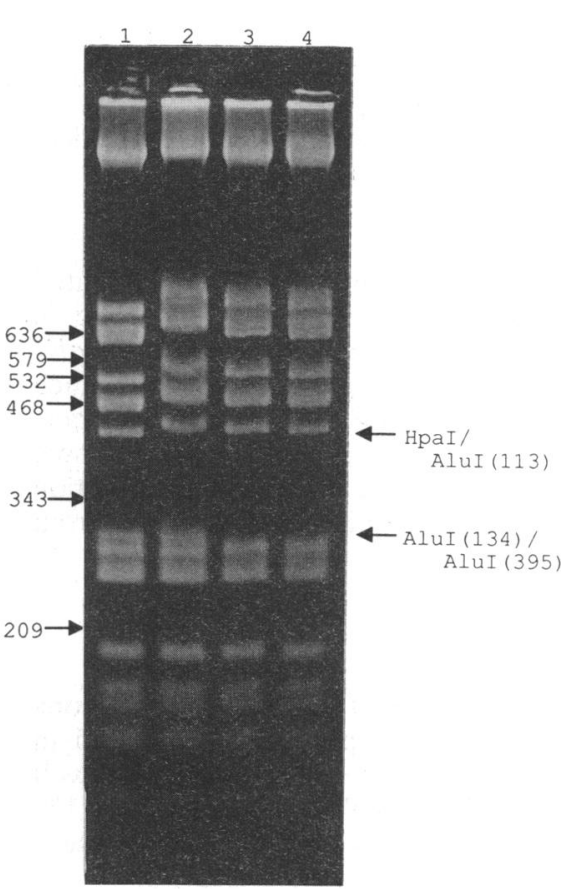

FIG. 7. Gel retardation as a result of TraA binding to DNA. Plasmid pAM7500 was digested with a restriction enzyme(s) and analyzed by gel electrophoresis as described in Materials and Methods. (A) DraI digest. Lanes: 1, control (no protein added); 2, protein fraction from control strain added; 3, TraA fraction added. (B) RsaI digest. Lanes: 1, control (no protein added); 2, protein fraction from control strain added; 3, TraA fraction added. Arrows on the right sides of panels A and B indicate bands that shifted. (C) HpaI-AluI digest. Lanes: 1 , control (no protein added); 2, protein fraction from control strain added; 3 and 4, TraA fraction added. Equivalent amounts of protein were added in each case. The numbers in parentheses after the names of the restriction enzymes indicate the positions of the corresponding restriction sites in Fig. 3. Molecular size markers (in base pairs) are shown on the left sides of the gels. 


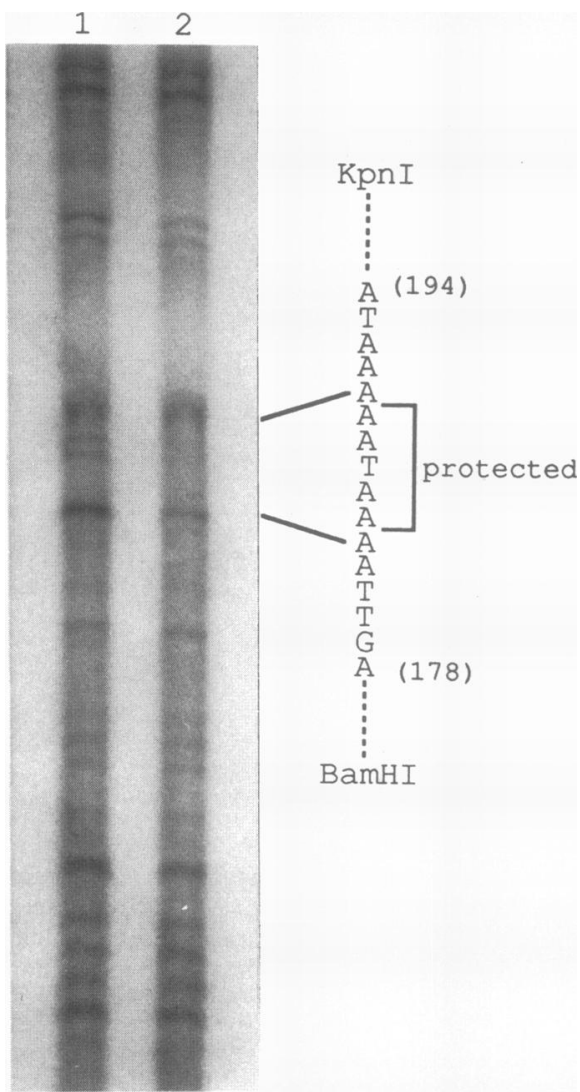

FIG. 8. DNA footprinting with TraA. The KpnI-BamHI fragment of pAM2610 was mixed with (lane 2) or without (lane 1) TraA, digested with DNase $I$, and run on a sequencing gel as described in Materials and Methods. A sequencing reaction (not shown) was run in parallel to position the region of protection. The nucleotides protected are indicated on the right.

the absence of the iad promoter in pAM2622 eliminated complementation. The data are reasonably conclusive in revealing the requirement for the iad promoter for traE1 expression, at least for the initial stages of induction. Since the transcription data identified an RNA species ( $\mathrm{m}^{\prime}$ ) corresponding to traE1 and being expressed from its own promoter, it is evident that at some stage in the induction process, expression no longer requires transcription from the iad promoter.

\section{DISCUSSION}

The previously reported analysis of transcriptional fusions (24) implied that induction by the pheromone resulted in significant read-through of putative terminator TTS1 as well as a second possible terminator (TTS2) located about 125 bases further downstream. Our RNA analyses in the present study yielded data consistent with those observations and provided additional insight into these events. Read-through from the iad promoter to the end of traE1 (transcript m2) appeared maximal at 20 min of induction, after which it became significantly reduced so that it was barely detectable at $80 \mathrm{~min}$. A separate transcript, $\mathrm{m3}^{\prime}$, appearing to be expressed under the control of the traE1 promoter, was also induced; this transcript, however, continued to be expressed well beyond the time at which the larger read-through transcript $(\mathrm{m} 2)$ became undetectable. The $\mathrm{m} 3^{\prime}$ signal was strong even after $160 \mathrm{~min}$ of pheromone exposure.

The transcription data suggest that the expression of traE1 initially requires read-through of TTS1 and TTS2 and that this may in turn trigger the expression of the gene from its own promoter. In this regard, it is noteworthy that Galli et al. (14) recently identified a transcriptional start site upstream of traE1 in the right repeat of TTS2. One interpretation is that activation of the traE1 promoter is somehow coupled to transcription from upstream through TTS2. However, considering the fact that TraE1 is a positively acting regulator at one or more sites downstream, it is very possible that it activates its own promoter as well. Thus, once enough TraE1 can be made as a result of transcriptional readthrough, it could begin to activate transcription from its own promoter. Consistent with this view were the results of the traE1 complementation studies, indicating again that TraE1 synthesis must initially utilize the iad promoter.

In addition to the increased read-through of TTS1 and TTS2, our studies indicated that during the first 20 to $40 \mathrm{~min}$ of pheromone exposure, the initiation of transcription from the iad promoter was significantly increased over its already relatively high basal level of expression. The precise location of this promoter was identified, and the highly dominant transcript, $\mathrm{m} 3$, corresponded to an RNA molecule terminating in the TTS1-TTS2 region. The data suggested that $\mathrm{IAD} 1$ should be detected in culture supernatants at a much higher level for induced cells compared with that normally observed for uninduced cells; however, we detected only about a twofold increase. It is not clear why the levels of $\mathrm{iAD} 1$ were not higher; nonetheless, the data were consistent with those observed for traA mutants, which also exhibited only a twofold increase $(28,30)$. Conceivably, iAD1 can be modified (inactivated) posttranslationally, or there may be factors limiting its processing and/or secretion. (It should be kept in mind that the peptide is synthesized as a 22-aminoacid precursor with the carboxy-terminal 8 residues corresponding to $\mathrm{iAD} 1$ [7].) With regard to traA mutants, the transcription pattern resembled that observed for a 20minute pheromone exposure of wild-type cells. It was previously reported by Pontius and Clewell (24) that a transcriptional fusion about 40 bases downstream of iad (pAM7304) expressed LacZ at similar levels (relatively high) both before and after exposure to cAD1. However, the postinduction LacZ determination was done after $90 \mathrm{~min}$, a time at which the transcription analyses reported in the present study indicated a reduction in $\mathrm{m} 3$ levels to nearly preinduction levels. The levels of the $\mathrm{m} 4$ and $\mathrm{m} 5$ RNAs detected did not change much during induction. These RNAs were shorter versions of transcripts for which no obvious terminators were evident in the sequence; conceivably they represent processed (or degraded) forms of $\mathrm{m} 3$, and their generation may be influenced by signals in the nucleotide sequence between the end of iad and TTS1. (See reference 24 for a discussion of a potential complex secondary structure that may occur in this region.)

Our DNA binding studies showed that the trans-acting TraA protein was associated with the promoter region of $i a d$, an observation consistent with the notion that TraA negatively regulates transcription from this region. It had been anticipated that TraA might act between iad and TTS1 to prevent transcriptional read-through; however, our inability to detect binding within this region implies that if TraA does indeed affect read-through, it is weak or requires additional factors. The possible involvement of a short (14-amino-acid- 


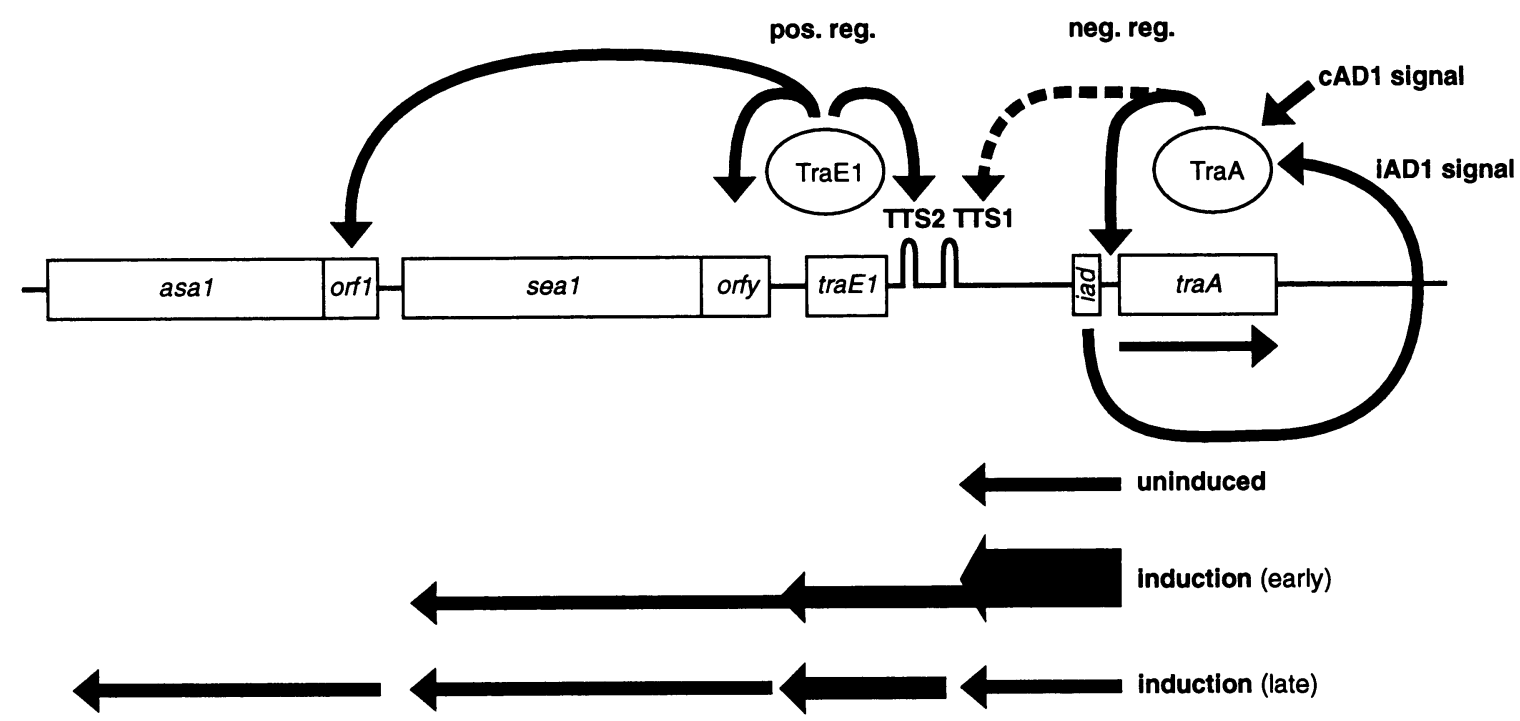

FIG. 9. Model for the regulation of the pAD1 pheromone response. Induction is viewed as the pheromone signal initially causing the release of the negative effect of TraA on the iad promoter as well as possibly effecting a transcription antitermination event at TTS1 and TTS2, allowing increased transcription and read-through into traE1. Once the TraE1 product is made, it positively self-regulates at the traE1 promoter as well as at the downstream promoters of sea1 and asa1. TraA repression resumes quickly, in part influenced by the burst of iAD1 expression that then competes with the cAD1 signal and also possibly due to derepression of $\operatorname{tra} A$ (i.e., a transient increase in TraA then negatively regulates itself). pos. reg., positive regulation; neg. reg., negative regulation.

residue) open reading frame starting within TTS1 $(7,29)$ should be kept in mind.

We could not detect TraA binding closer to or within the $\operatorname{tra} A$ promoter. However, the fact that footprinting experiments revealed a DNase insensitivity of this region in the absence of TraA made it difficult to rule out binding. A self-regulation of $\operatorname{traA}$ by its product would seem a reasonable possibility. However, Tn917lac insertions in traA, generating transcriptional fusions, result in very low levels of LacZ synthesis (28), implying that if derepression occurs, the increased level of TraA synthesis still involves a relatively low level of transcription. This result would not be surprising for a negatively acting regulatory protein.

Weidlich et al. (32) recently identified the determinant for surface exclusion protein Sea1, which is a $98-\mathrm{kDa}$ protein encoded downstream from traE1 (Fig. 1). Immediately preceding seal is an open reading frame, orfy, which would encode a $12-\mathrm{kDa}$ protein. Our Northern blot analyses identified an inducible RNA species, $\mathrm{m} 1$, that would easily correspond to a transcript extending to the $3^{\prime}$ end of seal. The data are consistent with the notion that the surface exclusion property of pAD1 is indeed inducible (6). Larger RNA species that might reflect extension into the determinant for the aggregation substance, asal (15), were not observed. Galli et al. (14) reported that both seal and asal can be transcribed independently from promoters upstream of orfy and orf1 (small reading frames just upstream of sea 1 and asa 1), respectively.

The model shown in Fig. 9 illustrates our current working hypothesis for how the various elements of regulation interact. It differs from a model recently proposed by Galli et al. (14) that does not view traE1 as able to be transcribed independently. These workers suggested that TraE1 activates the iad promoter to enhance the synthesis of transcripts reading through TTS1 TTS2. Their primer extension study revealed a transcriptional start site that was close to the traE1 translational start site and that was interpreted as an artifact relating to a secondary structure (TTS2) present in an RNA molecule extending further upstream (i.e., to the iad promoter). We believe that their inability to detect the traE1 transcript (our $\mathrm{m}^{\prime}$ transcript) was because of the electrophoresis conditions that they used, which would have allowed this small RNA species to migrate off the end of the gel. We believe that their data are actually consistent with our model.

Finally, it is worth noting that conjugative $E$. faecalis plasmid pCF10 appears in some ways to be organized in a manner similar to $\mathrm{pAD} 1(11,19)$. Both plasmids have a regulatory region adjacent to a surface exclusion determinant, which is in turn next to the gene for the aggregation substance. Like pAD1, pCF10 contains both positively and negatively acting regulatory products. The pheromones, however, are different, and there are recent indications that there are significant differences in the mechanisms of regulation (3).

\section{ACKNOWLEDGMENTS}

We thank Y. Su, D. Heath, F. An, and R. Wirth for helpful discussions relating to different aspects of this work.

This study was supported by Public Health Service grants GM33956 and AI10318 from the National Institutes of Health.

\section{REFERENCES}

1. Ausubel, F. M., R. Brent, R. E. Kingston, D. D. Moor, J. G. Seidman, J. A. Smith, and K. Struhl. 1987. Current protocols in molecular biology. John Wiley \& Sons, Inc., New York.

2. Chen, E. Y., and P. H. Seeburg. 1985. Supercoiled sequencing: a fast and simple method for sequencing plasmid DNA. DNA 4:165-170.

3. Chung, J. W., and G. M. Dunny. 1992. A cis-acting, orientationdependent, positive control system activates pheromone-inducible conjugation functions at distances greater than 10 kilobases upstream from its target in Enterococcus faecalis. Proc. Natl. Acad. Sci. USA 89:9020-9024.

4. Clewell, D. B. Sex pheromones and the plasmid-encoded mating 
response in Enterococcus faecalis. In D. B. Clewell (ed.), Bacterial conjugation, in press. Plenum Press, New York.

5. Clewell, D. B., F. Y. An, M. Mori, Y. Ike, and A. Suzuki. 1987. Streptococcus faecalis sex pheromone (cAD1) response: evidence that the peptide inhibitor excreted by pAD1-containing cells may be plasmid determined. Plasmid 17:65-68.

6. Clewell, D. B., and B. L. Brown. 1980 . Sex pheromone cAD1 in Streptococcus faecalis: induction of a function related to plasmid transfer. J. Bacteriol. 143:1063-1065.

7. Clewell, D. B., L. T. Pontius, F. Y. An, Y. Ike, A. Suzuki, and J. Nakayama. 1990. Nucleotide sequence of the sex pheromone inhibitor (iAD1) determinant of Enterococcus faecalis conjugative plasmid pAD1. Plasmid 24:156-161.

8. Clewell, D. B., P. K. Tomich, M. C. Gawron-Burke, A. E. Franke, Y. Yagi, and F. Y. An. 1982. Mapping of Streptococcus faecalis plasmids $\mathrm{pAD} 1$ and $\mathrm{pAD} 2$ and studies relating to transposition of Tn917. J. Bacteriol. 152:1220-1230.

9. Clewell, D. B., and K. E. Weaver. 1989. Sex pheromones and plasmid transfer in Enterococcus faecalis. Plasmid 21:175-184.

10. Davis, R. W., D. Botstein, and J. R. Roth. 1980. Advanced bacterial genetics. Cold Spring Harbor Laboratory, Cold Spring Harbor, N.Y.

11. Dunny, G. M. 1990. Genetic functions and cell-cell interactions in the pheromone-inducible plasmid transfer system of Enterococcus faecalis. Mol. Microbiol. 4:689-696.

12. Ehrenfeld, E. E., and D. B. Clewell. 1987. Transfer functions of the Streptococcus faecalis plasmid pAD1: organization of plasmid DNA encoding response to sex pheromone. J. Bacteriol. 169:3473-3481.

13. Ehrenfeld, E. E., R. E. Kessler, and D. B. Clewell. 1986. Identification of pheromone-induced surface proteins in Streptococcus faecalis and evidence of a role for lipoteichoic acid in formation of mating aggregates. J. Bacteriol. 168:6-12.

14. Galli, D., A. Friesenegger, and R. Wirth. 1992. Transcriptional control of sex-pheromone-inducible genes on plasmid pAD1 of Enterococcus faecalis and sequence analysis of a third structural gene for (pPD1-encoded) aggregation substance. Mol. Microbiol. 6:1297-1308.

15. Galli, D., F. Lottspeich, and R. Wirth. 1990. Sequence analysis of Enterococcus faecalis aggregation substance encoded by the sex pheromone plasmid pAD1. Mol. Microbiol. 4:895-904.

16. Galli, D., R. Wirth, and G. Wanner. 1989. Identification of aggregation substances of Enterococcus faecalis cells after induction by sex pheromones-an immunological and ultrastructural investigation. Arch. Microbiol. 151:486-490.

17. Ike, Y., and D. B. Clewell. 1984. Genetic analysis of the pAD1 pheromone response in Streptococcus faecalis, using transposon $\mathrm{Tn} 917$ as an insertional mutagen. J. Bacteriol. 158:777-783.

18. Ike, Y., R. A. Craig, B. A. White, Y. Yagi, and D. B. Clewell. 1983. Modification of Streptococcus faecalis sex pheromones after acquisition of plasmid DNA. Proc. Natl. Acad. Sci. USA 80:5369-5373.

19. Kao, S., S. B. Olmsted, A. S. Viksnins, J. C. Gallo, and G. M. Dunny. 1991. Molecular and genetic analysis of a region of plasmid pCF10 containing positive control genes and structural genes encoding surface proteins involved in pheromone-inducible conjugation in Enterococcus faecalis. J. Bacteriol. 173: $7650-7664$.

20. Mori, M., A. Isogai, Y. Sakagami, M. Fujino, C. Kitada, D. B.
Clewell, and A. Suzuki. 1986. Isolation and structure of the Streptococcus faecalis sex pheromone inhibitor, $\mathrm{iAD1}$, that is excreted by the donor strain harboring plasmid pAD1. Agric. Biol. Chem. 50:539-541.

21. Mori, M., Y. Sakagami, M. Narita, A. Isogai, M. Fujino, C. Kitada, R. Craig, D. B. Clewell, and A. Suzuki. 1984. Isolation and structure of the bacterial sex pheromone, cAD1, that induces plasmid transfer in Streptococcus faecalis. FEBS Lett. 178:97-100.

22. Pontius, L. T., and D. B. Clewell. 1991. A phase variation event that activates conjugation functions encoded by the Enterococcus faecalis plasmid pAD1. Plasmid 26:172-185.

23. Pontius, L. T., and D. B. Clewell. 1992. Regulation of the pAD1-encoded pheromone response in Enterococcus faecalis: nucleotide sequence analysis of $\operatorname{traA}$. J. Bacteriol. 174:18211827.

24. Pontius, L. T., and D. B. Clewell. 1992. Conjugative transfer of Enterococcus faecalis plasmid pAD1: nucleotide sequence and transcriptional fusion analysis of a region involved in positive regulation. J. Bacteriol. 174:3152-3160.

25. Shaw, J. H., and D. B. Clewell. 1985. Complete nucleotide sequence of macrolide-lincosamide-streptogramin B resistance transposon Tn917 in Streptococcus faecalis. J. Bacteriol. 164: 782-796.

26. Tanimoto, $K_{\text {., }}$ and T. Iino. 1985. Additional genes essential for replication of the mini-F plasmid from origin I. Mol. Gen. Genet. 198:358-359.

27. Tomich, P. K., F. Y. An, S. P. Damle, and D. B. Clewell. 1979. Plasmid-related transmissibility and multiple drug resistance in Streptococcus faecalis subsp. zymogenes DS16. Antimicrob. Agents Chemother. 15:828-830.

28. Weaver, K. E., and D. B. Clewell. 1988. Regulation of the pAD1 sex pheromone response in Enterococcus faecalis: construction and characterization of $l a c Z$ transcriptional fusions in a key control region of the plasmid. J. Bacteriol. 170:4343-4352.

29. Weaver, K. E., and D. B. Clewell. 1989. Construction of Enterococcus faecalis pAD1 miniplasmids: identification of a minimal pheromone response regulatory region and evaluation of a novel pheromone-dependent growth inhibition. Plasmid 22:106-119.

30. Weaver, K. E., and D. B. Clewell. 1990. Regulation of the pAD1 sex pheromone response in Enterococcus faecalis: effects of host strain and $\operatorname{tra} A, \operatorname{tra} B$, and $C$ region mutants on expression of an $\mathrm{E}$ region pheromone-inducible lacZ fusion. J. Bacteriol. 172:2633-2641.

31. Weaver, K. E., and D. B. Clewell. 1991. Control of Enterococcus faecalis sex pheromone cAD1 elaboration: effects of culture aeration and pAD1 plasmid-encoded determinants. Plasmid 25:177-189.

32. Weidlich, G., R. Wirth, and D. Galli. Sex pheromone plasmid pADl-encoded surface exclusion protein of Enterococcus faecalis. Mol. Gen. Genet., in press.

33. Wirth, R., F. An, and D. B. Clewell. 1986. Highly efficient protoplast transformation system for Streptococcus faecalis and a new Escherichia coli-S. faecalis shuttle vector. J. Bacteriol. 165:831-836.

34. Yagi, Y., and D. B. Clewell. 1980. Recombination-deficient mutant of Streptococcus faecalis. J. Bacteriol. 143:966-970. 